\title{
Dramaturgia no corpo
}

\author{
In-bodied Dramaturgy
}

Dramaturgie en-corps

Paola Secchin Braga *

http://dx.doi.org/10.22409/poiesis.1932.121-134

\begin{abstract}
RESUMO: O presente artigo tem por objetivo propor uma nova forma de dramaturgia para a dança, a dramaturgia no corpo. A partir dos conceitos de corporeidade (Michel Bernard) e estados do corpo (Philippe Guisgand), a autora propõe um novo caminho para a compreensão do corpo enquanto criador de ficções em dança. A corporeidade dançante é vista como o lugar onde o conhecimento é processado e ela se torna o locus da produção de sentido. A introdução do espectador nesta equação se torna primordial, pois o sentido do gesto dançado somente é concretizado no momento em que há interação entre performer e espectador.
\end{abstract}

PALAVRAS-CHAVE: dramaturgia da dança; corpo; corporeidade; criação de ficção; produção de sentido

\footnotetext{
* Paola Secchin Braga é doutora em dança pela Universidade Paris 8, onde desenvolveu uma pesquisa sobre a representação dos corpos em trabalhos biográficos em dança. Atualmente, é Conselheira da programação pedagógica no CN D - Centre National de la Danse, na França. E-mail: paolasecchinbraga@gmail.com
} 
ABSTRACT: This article's intention is to propose a new type of dance dramaturgy: the in-bodied dramaturgy. Using the concepts of corporeity (Michel Bernard) and of the states of the body (Philippe Guisgand), the author proposes a new path for the comprehension of the body as a creator of fiction in dance. The dancing corporeity is seen as the place where knowledge is processed and it becomes the locus of the production of sense (meaning). The introduction of the spectator in this equation becomes essential, once the danced gesture is materialized only at the moment of interaction between performer and spectator.

KEYWORDS: dance dramaturgy; body; corporeity; creation of fiction; production of sense

RÉSUMÉ: L'enjeu de cet article est de proposer une nouvelle forme de dramaturgie de la danse, la dramaturgie en-corps. Partant des concepts de corporéité (Michel Bernard) et d'états de corps (Philippe Guisgand), l'auteur propose une nouvelle forme de compréhension du corps en tant que créateur de fictions en danse. La corporéité dansante est vue comme le lieu où les savoirs sont traités et elle devient le lieu de production de sens. L'introduction du spectateur dans cette équation devient essentielle, car le sens du geste dansé ne se donne qu'au moment où il $\mathrm{y}$ a interaction entre performeur et public.

MOTS-CLÉS: dramaturgie de la danse; corps; corporéité; création de fiction; création de sens

Recebido: 31/10/2018; Aprovado: 8/12/2018

Como citar: BRAGA, Paola Secchin. Dramaturgia no corpo. Poiésis, Niterói, v. 19, n. 32, p. 121-134, jul./dez. 2018.

doi: http://dx.doi.org/10.22409/poiesis.1932.121-134

Poiésis, Niterói, v. 19, n. 32, jul./dez. 2018. 


\section{Dramaturgia no corpo}

A partir do fim da década de 1980, intensificou-se a discussão a respeito do que seria uma dramaturgia da dança e de qual seria a função de um dramaturgo de dança. Questões como quais as razões da grande demanda por dramaturgos junto às companhias de dança a partir do advento da dança contemporânea; ou ainda, qual seria objeto de estudo do dramaturgo de dança que ocupava, então, as mentes e engordava a produção literária. Não nos deteremos aqui nessas discussões ${ }^{1}$, pois muito já foi dito relacionando à figura do dramaturgo com o trabalho coreográfico em si, com a dinâmica de produção do espetáculo e com os corpos que povoam esse trabalho. Nos concentraremos nestes últimos, os corpos dos dançarinos, que nos interessam particularmente neste artigo. 
De maneira geral, concorda-se que a chamada dramaturgia da dança engloba uma série de ações por parte do dramaturgo que orbitam em torno da produção de sentido na obra. Esse sentido poderia ser encontrado em duas condições: seja através da linha mais tradicional de trabalho dramatúrgico da escola alemã, na qual o dramaturgo ajuda o metteur en scène, antes do início dos ensaios, a encontrar o sentido, o conceito, que norteará a construção da obra; seja quando o sentido é encontrado através e ao longo do processo de construção da obra. Esta última filosofia de trabalho é, segundo a dramaturga e escritora Marianne van Kerkhoven ${ }^{2}$, a que melhor se aplicaria em uma prática ligada à dança:

[...] escolhemos trabalhar com matérias de origens diversas (textos, movimentos, imagens de filmes, objetos, ideias etc.); 0 "material humano" (os atores/os dançarinos) é decididamente o mais importante; a personalidade dos performers, mais do que suas habilidades técnicas, é considerada como o fundamento da criação. 0 metteur en scène ou o coreógrafo inicia 0 trabalho com estes materiais; durante o processo de ensaio, ele/ela observa como esses materiais se comportam e se desenvolvem; é somente no fim desse processo que aparece lentamente um conceito, uma estrutura, uma forma mais ou menos definida; essa estrutura final não é conhecida desde o início. (KERKHOVEN, 1997, p. 32 [tradução nossa])

Guardemos em mente que o que interessa particularmente a uma dramaturgia da dança, segundo a autora, é o chamado "material humano", o performer.

Guy Cools, por sua vez, em seu artigo De la dramaturgie du corps en danse (Cools, 2005), indica que o dramaturgo teria por função, ao longo do processo de trabalho, estimular a intuição criativa, muitas vezes inconsciente, dos corpos dos dançarinos. Além disto, seria sua função também ajudar o coreógrafo a estruturar essa intuição dos corpos de acordo com sua lógica própria. Diz ele, ainda, que a dramaturgia atual é vista de uma maneira geral como uma ajuda dada ao artista para que ele possa encontrar sua própria "língua" e possa articulá-la da melhor maneira possível. Ele considera que "a dança se traduz com o corpo e na direção dele. Nisto, ela tem o poder de 'incorporar' literalmente o conhecimento e os conceitos de outras disciplinas artísticas e de outros campos de interesse humano." (COOLS, 2005, p. 91 [tradução nossa])

Poiésis, Niterói, v. 19, n. 32, jul./dez. 2018. 
Se concordarmos com Kerkhoven quando ela diz que o principal no trabalho dramatúrgico é o material humano, caminhamos para uma dramaturgia que giraria em torno de um ponto central, o performer. Consequentemente, o que é específico do performer, o que ele tem de único nos interessa - sua personalidade, como diz a autora, suas experiências e seu corpo. E se, por outro lado, pensarmos com Cools no objetivo do trabalho dramatúrgico em dança como sendo estimular a intuição criativa dos corpos dos dançarinos, poderíamos dizer que a dramaturgia em dança teria por objeto de trabalho os corpos dos performers e estaria concentrada no estímulo à sua intuição criativa.

A dramaturgia da dança parece, então, se configurar como orientada e objetivada para o corpo e para o trabalho deste corpo.

E que corpo é esse? De que corpo estamos falando? Como ele funciona? Como se processa a "estimulação da intuição dos corpos"? O que vem a ser a intuição dos corpos? Tais perguntas vão nos orientar ao longo deste artigo e nos guiarão no estabelecimento de um novo olhar, de uma proposta distinta de dramaturgia da corporeidade dançante.

Iniciamos, então, esta empreitada definindo nosso ponto de partida: o corpo. Consideramos o corpo enquanto corporeidade, no sentido que lhe é atribuído pelo filósofo francês Michel Bernard em seu artigo De la corporéité comme "anticorps" (BERNARD, 2001a). Bernard abandona o uso do termo corpo por considerar que este não é inocente e que, ao ser utilizado, já coloca em obra

0 simulacro da experiência vivida que ele pretende designar e acreditar como realidade objetiva, como ser em si e por si. Em outras palavras, a palavra "corpo" se apresenta como autofundadora de seu referente: ela legitima a priori a crença que anima secretamente a abordagem e a aproximação pela qual ela apreende este referente e que é, bem entendido, a emanação de uma cultura específica e de sua história. (BERNARD, 2001a, p. 17 [tradução nossa])

Em lugar da palavra corpo, que nos daria a noção de uma entidade estável, constante e imutável, Bernard propõe o termo corporeidade (corporéité) que traria "uma visão original, ao mesmo tempo plural, dinâmica e aleatória, como jogo quiasmático instável de for- 
ças intensivas ou de vetores heterogêneos." (BERNARD, 2001a, p. 21 [tradução nossa]) Tal termo vem carregado de conotações plásticas e espectrais. Entender o corpo dançante enquanto corporeidade dançante significa entrar em contato com um corpo poroso, quiasmático, atravessado por forças diversas que o modificam, por vetores que constantemente o alteram. Não um corpo dado e estável, mas uma corporeidade em contínua mutação, em eterna adaptação. Uma corporeidade sujeita a sensações diversas e distintas, que se entrecruzam e agem umas sobre as outras, trazendo alterações no seu funcionamento.

Nosso "material humano", interesse principal dessa dramaturgia específica da dança, torna-se dinâmico e mutável, uma vez compreendido como corporeidade. Poderíamos talvez já começar a pensar em uma dramaturgia específica de uma corporeidade dançante. E se, como Cools defende, a dança se traduz com o corpo, in-corporando - trazendo para dentro do corpo - conhecimentos e conceitos, podemos pensar que a corporeidade dançante traz o conhecimento para seu corpo e é, consequentemente, atravessada, transformada por ele. É no corpo, na própria carne, que o conhecimento toma forma. O conhecimento é, literalmente, encarnado na corporeidade dançante.

Em outro artigo, Bernard (2001b) fala de uma característica dessa corporeidade, a de simulação, a capacidade de criar ficções a partir das sensações corporais: "[...] todas as nossas sensações não se contentam em dialogar entre elas ou de ressoar umas nas outras, mas elas tecem entre si uma textura corporal fictícia, móvel, instável que habita nossa corporeidade aparente e a desdobra, tal como o ato de enunciação linguístico." (BERNARD, 2001b, p. 99 [tradução nossa]) Revendo o que foi dito, tal como o ato de enunciação, as sensações que chegam a uma corporeidade, a percorrem e criam ficções que a habitam e a desdobram. Passamos a compreender, então, a corporeidade como produtora de desdobramentos, de ficções criadas a partir de sensações. Mais adiante, Bernard continua: "[...] o complexo trabalho sensorial do dançarino traz nele mesmo uma ficção originária que ele exibe, desdobra e veicula por sua mera performance cênica." (BERNARD, 2001b, p. 100 [tradução nossa]). E é na performance cênica que a ficção criada pela corporeidade do dançarino é desdobrada e exibida.

Poiésis, Niterói, v. 19, n. 32, jul./dez. 2018. 
Temos então o conhecimento encarnado, presente na carne de uma corporeidade que cria ficções a partir de suas sensações. Pensamos que é por essa corporeidade dançante "ficcionadora", "encarnadora" que uma dramaturgia da corporeidade dançante se interessaria.

Gostaríamos ainda de trazer mais um conceito para nos ajudar a construir nosso ponto de vista, o conceito de estado do corpo. O filósofo francês Philippe Guisgand define por estado do corpo "o conjunto das tensões e das intenções que se acumulam interiormente e vibram exteriormente, e a partir do qual o espectador pode reconstituir uma genealogia das intensidades que presidem à forma." (GUISGAND, 2012, p. 242 [tradução nossa]) Tensões e intenções que vibram interiormente e, consequentemente, transparecem exteriormente, um elo a partir do qual é estabelecido um contato entre o corpo do dançarino e o do espectador. Essa expressão remete a uma qualidade de dança particular, tanto para aquele que a produz, quanto para aquele que a assiste. Ela nos remete ao duplo sentido do termo interpretação:

0 dançarino é intérprete, tornando visíveis as formas corporais, mas ele deve igualmente motivar seu movimento, reencontrar 0 que presidiu sua criação. 0 gesto dançado aparece, então, colorido por uma intenção, uma carga emocional, um desejo que o espectador tenta, por sua vez, interpretar. (GUISGAND, 2012, p. 224 [tradução nossa])

A noção de estado do corpo vem atrelada a uma ideia de intencionalidade, os dançarinos se preparam para acessar um estado específico em determinados momentos, eles se colocam em certos estados de corpo no momento em que atuam, em que apresentam sua dança. Estados esses que dependem do conjunto de tensões e de intenções acumuladas interiormente e que vêm a vibrar exteriormente. Mais uma vez, vemos a corporeidade dançante sendo atravessada, alterada, pelo que Guisgand chama de tensões, o que Bernard chama de sensações, que são in-corporadas, criando ficções encarnadas nessa corporeidade dançante. Guisgand chama ainda a nossa atenção para o fato de que tais tensões e intenções vibram externamente, elas são o desencadeador da reação do espectador. É a partir dessas vibrações externas que o espectador poderá "reconstituir uma genealogia das intensidades que presidem à forma". Ou seja, é a partir delas que a relação 
entre performer e espectador é desencadeada, e que o sentido do gesto dançado é compartilhado.

Revendo o que foi dito acima, nosso olhar na direção de uma dramaturgia da dança, na direção da criação de sentido através do gesto dançado é conduzido para o corpo do performer. Uma dramaturgia de uma corporeidade dançante, criadora de ficções, que estabelecem a relação com o espectador e possibilitam o surgimento, o afloramento, do sentido da performance dançada. O locus da produção de sentido se fixa então na corporeidade dançante e é nela que uma dramaturgia da dança deve se concentrar.

O que motiva o trabalho criativo do performer de dança? Onde se origina essa motivação? De que modo funciona? Como pode ser trabalhada? Todas essas perguntas nos colocam em contato com essa corporeidade dançante, seus atravessamentos e sua capacidade de ficção. Uma corporeidade com intuição criativa, capaz de ficcionar, passa a ser nosso ponto de interesse quando se fala de dramaturgia da dança. A tentativa de se acessar, de se colocar em marcha a intuição criativa do corpo do performer está em íntima relação com a compreensão do funcionamento dessa corporeidade dinâmica, capaz de ficção. De forma semelhante, os diferentes estados do corpo do dançarino nos aproximam do locus da criação de sentido na obra, a corporeidade dançante. Logo, compreendemos a dramaturgia não mais como uma dramaturgia da dança ou do corpo, mas sim como uma dramaturgia no corpo, criada, ficcionada, elaborada e compartilhada no corpo e a partir dele. Propomos pensar uma dramaturgia encarnada, ficções passíveis de compreensão somente se pensadas a partir da corporeidade dançante e de seus estados de corpo.

Como auxílio para a compreensão de nosso ponto de vista, veremos em seguida alguns casos que podem esclarecer como tal ideia de uma dramaturgia no corpo se daria na prática.

Observando-se, em primeiro lugar, o percurso da Marcia Milhazes Dança Contemporânea3 podemos distinguir dois níveis de compreensão dos corpos: significação e impressão. Por um lado, é clara e facilmente reconhecível a marca coreográfica de Marcia Milhazes. Em

Poiésis, Niterói, v. 19, n. 32, jul./dez. 2018. 
todos os trabalhos da coreógrafa para a companhia - que pudemos observar de 1995 até o presente, com Guarde-me, a última produção da companhia - a assinatura de Milhazes nos corpos é inconfundível ${ }^{4}$. Mesmo com diversos e diferentes corpos participando da companhia ao longo de mais de duas décadas, reconhecemos facilmente uma transformação, uma adaptação destes à compreensão que Milhazes tem do corpo em seus trabalhos. Ao se assistir Santa Cruz (1995), Tempo de verão (2004), Meu prazer, (2008), Sempre Seu (2016) ou Guarde-me (2017), dentre outros, podemos conhecer e reconhecer a assinatura corporal que Milhazes instaurou nos diferentes corpos dos bailarinos que povoaram a companhia. A compreensão que a coreógrafa tem do corpo atravessa as corporeidades dançantes dos bailarinos e os guia na formação de ficções. É nesse corpo, atravessado pela compreensão específica de corpo que Milhazes tem, que o sentido das peças é formado. A "língua" própria da coreógrafa se traduz no corpo do dançarino. Por outro lado, tais corpos, tão diferentes entre si - e aqui lembramos da própria Marcia Milhazes dançando, de Luciana Yegros, Al Crispim, Ana Amélia Vianna, Pim Boonprabok, Aline Arakari e Felipe Padilha, para citar apenas alguns - apesar de absorverem neles mesmos uma escrita tão nítida e precisa quanto a de Milhazes, mantêm sua singularidade intacta. Tais corpos, atravessados por sensações e experiências diversas em sua formação e em sua vida processam de maneiras diferentes o material coreográfico e a escrita artística de MiIhazes. Eles não se tornam cópias conformes de um corpo idealizado pela coreógrafa, mas são o resultado de um entrecruzamento produzido nos corpos, e que torna possível que cada um "fale a língua" da coreógrafa de sua própria maneira. É nesses corpos que o conhecimento - tanto o adquirido ao longo de suas experiências artísticas e de vida, quanto aquele adquirido através do contato com o material coreográfico e a linguagem artística de Milhazes - será in-corporado, encarnado, e passará a produzir suas ficções. E será através do contato destes corpos singularmente formados com o corpo do espectador que o material coreográfico adquirirá sentido. Do corpo do coreógrafo para o corpo do performer, e finalizando esta sequência com a experiência corporal que o espectador vivencia ao assistir o corpo do bailarino em ação. De corpo para corpo, nos corpos. De corporeidade para corporeidade. Todas dinâmicas, todas porosas, todas passíveis de criar ficções. 
Em seguida, gostaríamos de analisar, ainda que brevemente, a série de trabalhos onomásticos do coreógrafo francês Jérôme Bel. Bel criou cinco trabalhos em que, baseado em um protocolo de interrogatório, ele desenha o perfil de cada dançarino e de suas experiências profissionais e apresenta o próprio dançarino contando e dançando sua história de vida em cena. As peças, que levam o nome de seus protagonistas, são:

- Véronique Doisneau estreou no Palais Garnier, Ópera de Paris, em 22 de setembro de 2004. Trata-se de uma bailarina clássica francesa, então trabalhando no corpo de baile da Ópera de Paris;

- $\quad$ Pichet Klunchun and Myself estreou no Bangkok Fringe Festival, Bangkok, em 12 de dezembro de 2004. P. Klunchun é tailandês, dançarino de Khôn, dança tradicional tailandesa;

- Isabel Torres estreou no Panorama Rio Dança, no Theatro Municipal do Rio de Janeiro, em 30 de outubro de 2005. I. Torres é bailarina brasileira de formação clássica e integra o corpo de baile do Theatro Municipal do Rio de Janeiro;

- $\quad$ Lutz Förster estreou no Springdance Festival, em Utrecht, em 16 de abril de 2009. Ele é alemão, bailarino do Tanztheater Wuppertal, de Pina Bausch;

- Cédric Andrieu estreou na Association pour la Danse Contemporaine, em Genebra, em $1^{\circ}$ de dezembro de 2009. C. Andrieux é francês e integrou a companhia de Merce Cunningham por oito anos.

Com diferentes perfis, de origens diversas, com formações díspares e experiências profissionais totalmente dessemelhantes, os cinco dançarinos seguem um protocolo específico e pré-determinado de postura, interpretação e forma de falar. A cenografia e a iluminação são idênticas em todas as peças e as perguntas que guiaram a criação dos textos obedecem a um só questionário. O efeito final das montagens, no que se refere à parte técnica e ao tratamento estético, é o mesmo. Contudo, cada corpo é um corpo, transformando a padronização de Bel em diferentes traduções, criando a diversidade enquanto vivência corporal.

Poiésis, Niterói, v. 19, n. 32, jul./dez. 2018. 
Os casos que gostaríamos de trazer aqui são os de Pichet Klunchun e de Lutz Förster.

Klunchun, profissional conceituado de Khôn, dança tradicional tailandesa, introduz um colorido imaginário à peça que leva seu nome, abrindo a oportunidade para o espectador criar e ficcionar junto e por meio do corpo dele. Mesmo mantendo os padrões impostos por Bel, com a postura neutra, e com o figurino básico de ensaio - camisa e calça pretas nas captações e fotos observadas -, Klunchun, através da intuição criativa de seu corpo, faz surgir diante de nós com gestos simples três personagens, uma mulher, um macaco e um demônio. Três estados de corpo facilmente detectáveis e reconhecíveis. Através de pequenos gestos a priori sem nenhuma significação, a corporeidade dinâmica do dançarino cria sentido diante de nossos olhos, instaurando em seu corpo uma ficção da qual nos permite participar. Seu corpo e suas diferentes dinâmicas colorem a movimentação bem pouco conhecida do público em geral, permitindo a comunicação de corpo para corpo. Uma dramaturgia no corpo, criada, ficcionada, elaborada e compartilhada no corpo e a partir dele.

Por outro lado, podemos ver em Lutz Förster o tiro sair pela culatra. O bailarino, que dançou com o Tazntheater Wuppertal de Pina Bausch por mais de trinta anos, não consegue abandonar o estado de corpo a que se acostumou ao longo dos anos de trabalho com a companhia. Tampouco consegue entrar no molde criado por J. Bel. Não consegue contar outra história com seu corpo a não ser aquela assumida em sua vida profissional pregressa. Colado no personagem Lutz-Förster-bailarino-de-Pina-Bausch, seu corpo pouco comunica com a plateia, toda informação que temos está no que diz seu texto. O corpo de Förster fica aprisionado na mais longa experiência de sua vida, e não consegue se integrar na proposta de Bel, não consegue criar um novo estado do corpo. Vemos dois estados de corpo existindo lado a lado, sem nenhuma integração. Por vezes, L. Förster procura reassumir a postura neutra indicada por Bel, para logo em seguida abandoná-la e, em um salto, voltar a ser o seu próprio personagem. Uma postura ou a outra. Um estado de corpo ou o outro. Nesse corpo não há integração das duas propostas. Mesmo com um texto longuíssimo, um dos mais longos dentre as cinco peças, ele não consegue cumprir a proposta do trabalho. Fica claro que somente o texto não basta, o corpo também precisa 
contar a história. Como consequência natural da falta de comunicação entre o corpo idealizado por Bel e o corpo vivido do dançarino, não há a produção de ficção. E, fatalmente, o corpo do espectador fica isolado, não participando na construção de sentido do trabaIho. Não é surpreendente que esta peça tenha tido uma carreira curta, com apenas 20 apresentações e, em seguida, tenha sido retirada do circuito.

Nossa proposta aqui, neste artigo, foi a de instaurar um possível e novo olhar dramatúrgico com relação à dança. Discutimos os conceitos de corporeidade e de estado do corpo para compreender onde se dá a produção de sentido na obra. Compreendemos o sentido do gesto dançado enquanto resultado de ficções criadas pelo corpo do performer envolvido no trabalho, e a interação deste corpo com o do espectador. É no corpo do performer, corpo poroso e expressivo, que o conhecimento se aloja, que mudanças são produzidas, e é nesse terreno fértil que pode aflorar o sentido do gesto dançado. Já dizia Merce Cunningham, o movimento é expressivo por si mesmo, independentemente de qualquer intenção de expressividade, para além da intenção (CUNNINGHAM, 1985). Porém, o movimento só toma forma no corpo do performer. E a dramaturgia passa a ter sentido somente enquanto uma dramaturgia encarnada, uma dramaturgia no corpo daquele que dança.

Poiésis, Niterói, v. 19, n. 32, jul./dez. 2018. 


\section{Referências}

BERNARD, Michel. De la corporeité comme 'anticorps'. In BERNARD, Michel. De la création chorégraphique. Pantin: Centre National de la Danse, 2001a, p. 17-24.

BERNARD, Michel. Sens et fiction-ou les effets étranges des trois chiasmes sensoriels. In BERNARD, Michel. De la création chorégraphique. Pantin: Centre National de la Danse, 2001b, p. 95-100.

COOLS, Guy, De la dramaturgie du corps en danse. Jeu: Revue Theatrale, Montreal, n. 116, p. 89-95, (3) 2005. Disponível em http://id.erudit.org/iderudit/2481ac. Acesso em março de 2016.

CUNNINGHAM, Merce. The Dancer and the Dance: Conversations with Jacqueline Lesschaeve. Nova York; Londres: Marion Boyars Publishers, 1985.

GUISGAND, Philippe. A propos de la notion d'état de corps. Palestra ministrada no Centre d'Etude des Arts Contemporains, Universidade Lille 3, em 2/02/11. Disponível em http://perso.univ-lille3.fr/ pguisgand/downloads/Etat\%20de\%20corpsTag\%20Cloud .pdf. Acesso em março de 2014.

KERKHOVEN, Marianne Van. Le processus dramaturgique (in Nouvelles de Danse). Contredanse, Bruxelas, n. 31, p. 18-25, 1997. 


\section{Notas}

\footnotetext{
1 Para maiores informações, indicamos os trabalhos de Marianne Van Kerkhoven, Scott deLahunta, Jean-Marc Adolphe e Bojana Cvejic.

${ }^{2}$ Marianne Van Kerkhoven colaborou com Anne Teresa de Keersmaeker em suas produções de 1985 a 1990.

${ }^{3}$ A companhia de dança carioca Marcia Milhazes Dança Contemporânea iniciou suas atividades em 1994, com o retorno da coreógrafa ao Brasil, após um período de estudos e formação em Londres, e permanece ativa até o presente. Para maiores informações, indicamos o site Wikidança.net, na URL: http://www.wikidanca.net/wiki/ index.php/M\%C3\%A1rcia_Milhazes_Dan\%C3\%A7a_Contempor\%C3\%A2nea.

${ }^{4}$ Remetemos o leitor aos seguintes links para poder observar mostras do trabalho de Milhazes: Meu prazer: https: //www.youtube.com/watch?v=d6s6EjPleyk Camélia: https: / / www. youtube.com/watch?v=KMKhcbhFVdE
} 